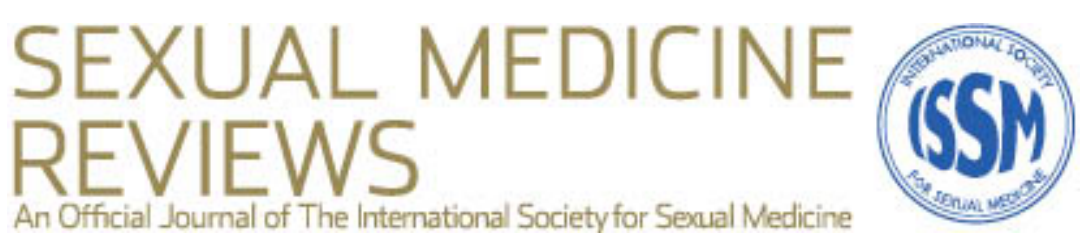

\title{
Sex hormone binding globulin: A review of its interactions with testosterone and age, and its impact on mortality in men with type 2 diabetes.
}

\begin{tabular}{|c|c|}
\hline Journal: & Sexual Medicine Reviews \\
\hline Manuscript ID & SMR-03-2019-015.R2 \\
\hline Aritcle type: & Review \\
\hline Subject Area: & Risk factors/co-morbidities < BASIC SCIENCE < MALE \\
\hline Keywords: & $\begin{array}{l}\text { sex hormone binding globulin, total testosterone, mortality, type } 2 \\
\text { diabetes, age, free and bioavailable testosterone }\end{array}$ \\
\hline Abstract: & $\begin{array}{l}\text { Abstract. } \\
\text { Introduction. The age-related fall in male testosterone levels can have } \\
\text { clinical consequences. The concentration of serum free testosterone, the } \\
\text { putative bioactive moiety, is mediated by carrier proteins especially sex } \\
\text { hormone binding globulin (SHBG). } \\
\text { Aim. We consider the nature of hormone binding to carriers with new } \\
\text { insights into determining calculated free testosterone levels and review } \\
\text { how SHBG and testosterone influence age-related mortality. } \\
\text { Methods. Where possible we focused on recent literature describing } \\
\text { binding of testosterone to carrier proteins or, associations between age, } \\
\text { SHBG, testosterone and mortality. We then used logistic regression to } \\
\text { study the impact of SHBG and total testosterone on age-related } \\
\text { mortality in men with type } 2 \text { diabetes (T2DM). } \\
\text { Main outcome measure. The association between mortality and age and } \\
\text { SHBG and / or total testosterone was determined in a cohort of } 364 \text { men } \\
\text { with T2DM leading to a graphical display of the impact of SHBG / } \\
\text { testosterone levels on age-related mortality. } \\
\text { Results. Low total testosterone and high SHBG are independently } \\
\text { associated with increased all-cause mortality. Our analyses support } \\
\text { these findings showing that men with T2DM and a combination of total } \\
\text { testosterone }<12 \text { nmol/l and SHBG }>35 \text { nmol/I (odds ratio (OR): } 3.05,95 \% \\
\text { CI: } 1.43-6.53, p=0.004) \text { demonstrated an increased risk of mortality, } \\
\text { independent of age (OR: } 1.08,95 \% \text { CI: } 1.06-1.11, \mathrm{p}<0.001) \text {. We } \\
\text { graphically demonstrated that the risk combination altered the } \\
\text { relationship between age and mortality. } \\
\text { Conclusions. Until free testosterone is precisely, accurately and } \\
\text { conveniently measured, calculated values may provide useful even if } \\
\text { somewhat inaccurate estimates. We also suggest that SHBG and } \\
\text { testosterone assays are standardised to allow establishment of } \\
\text { diagnostic and treatment thresholds. While it is possible the association } \\
\text { in men with T2DM, between the combination of SHBG and total } \\
\text { testosterone and age related mortality is driven by free hormone levels, } \\
\text { it is so far, unproven. }\end{array}$ \\
\hline
\end{tabular}




\section{SCHOLARONE" Manuscripts}




\begin{abstract}
.
Introduction. The age-related fall in male testosterone levels can have clinical consequences. The concentration of serum free testosterone, the putative bioactive moiety, is mediated by carrier proteins especially sex hormone binding globulin (SHBG).
\end{abstract}

Aim. We consider the nature of hormone binding to carriers with new insights into determining calculated free testosterone levels and review how SHBG and testosterone influence age-related mortality.

Methods. Where possible we focused on recent literature describing binding of testosterone to carrier proteins or, associations between age, SHBG, testosterone and mortality. We then used logistic regression to study the impact of SHBG and total testosterone on age-related mortality in men with type 2 diabetes (T2DM). Main outcome measure. The association between mortality and age and SHBG and / or total testosterone was determined in a cohort of 364 men with T2DM leading to a graphical display of the impact of SHBG / testosterone levels on age-related mortality.

Results. Low total testosterone and high SHBG are independently associated with increased all-cause mortality. Our analyses support these findings showing that men with T2DM and a combination of total testosterone $<12 \mathrm{nmol} / \mathrm{l}$ and SHBG $>35 \mathrm{nmol} / \mathrm{I}$ (odds ratio (OR): $3.05,95 \% \mathrm{Cl}: 1.43-6.53, \mathrm{p}=0.004)$ demonstrated an increased risk of mortality, independent of age (OR: $1.08,95 \% \mathrm{Cl}: 1.06-1.11, \mathrm{p}<0.001)$. We graphically demonstrated that the risk combination altered the relationship between age and mortality.

Conclusions. Until free testosterone is precisely, accurately and conveniently measured, calculated values may provide useful even if somewhat inaccurate 
estimates. We also suggest that SHBG and testosterone assays are standardised to allow establishment of diagnostic and treatment thresholds. While it is possible the association in men with T2DM, between the combination of SHBG and total testosterone and age related mortality is driven by free hormone levels, it is so far, unproven. 


\section{Introduction.}

The importance, particularly in men with type 2 diabetes (T2DM), of adult onset testosterone deficiency (TD), a combination of low serum testosterone and symptoms, is illustrated by research showing associations between low hormone levels and various pathologies and even mortality. [1] The mechanisms of these associations appear to involve serum proteins that transport testosterone and mediate the amounts of hormone that are in free solution or bioavailable. Serum sex hormone binding globulin (SHBG) has attracted particular attention as it appears critical in determining the serum level of these moieties which have been proposed as determinants of androgen activity (Figure 1). [2] Due to continuing uncertainties regarding some testosterone and SHBG assays and methods used to determine free and bioavailable testosterone, it seems clear that gaining a better understanding of the relationship between the hormone, SHBG and clinical phenotypes should help improve the diagnosis and management of men with symptoms of hypogonadism.

We firstly review data describing the clinical importance of maintaining adequate levels of testosterone and secondly consider the nature of hormone binding to its carriers and methods to estimate free and bioavailable testosterone. We thirdly, review studies indicating that SHBG is a clinically useful marker focusing on the finding that SHBG is independently associated with mortality in men with T2DM. Since age is strongly associated with mortality and SHBG and, appears to mediate the impact of SHBG and testosterone on mortality, we describe further analysis of data from our published study showing the impact of combinations of these predictors on the probability of age-related mortality. [3] The combination of low total testosterone and high SHBG in men aged>66 years is a principal risk category. 


\section{Clinical Importance of testosterone.}

Testosterone has varied functions in humans, perhaps the best recognized being in development of the male reproductive system [4]. Some of its other pleiotropic functions may become evident in older men as serum levels typically decline by about $30 \%$ between ages $40-90$ years $[5,6,7,8,9]$. Thus, symptoms of adult onset TD may include decreases in bone mineral density, muscle strength, cognitive and sexual function.[4,5,6,7,8,9] Adult onset TD is also associated with increased central obesity and insulin resistance and consequently, the metabolic syndrome (MetS) and T2DM. $[4,10,11,12,13,14,15,16]$ The prevalence of adult onset TD is high in T2DM and MetS patients; in our cohort about $70 \%$ of men with T2DM had low serum total testosterone levels (<12nmol/L) and sexual symptoms [12] though other studies have shown a lower prevalence of up to $40 \%$. [13,17] Importantly, both adult onset TD and erectile dysfunction are independently associated with increased mortality $[18,19,20]$ and, T2DM is linked with cardiovascular disease (CVD), sexual dysfunction and reduced life expectancy. [16] Independent studies show an association between low serum testosterone and adverse CVD events and all-cause mortality. [21,22,23,24,25,26,27,28] For example, the European Male Ageing study (2599 men, 7\% withT2DM, aged 40-79 years) showed that adult onset TD with total testosterone $<8 \mathrm{nmol} / /$ was significantly associated with increased total and CVD-related mortality [22]. That the reduced availability of testosterone is a causative factor is supported by data showing testosterone replacement (TTh) can lead to improved sexual health and reduced allcause mortality $[6,19,23,24,25]$. Shores et al showed TTh was associated with significantly reduced mortality in men with T2DM aged over 40 years and with total testosterone $\leq 8.7 \mathrm{nmol} / \mathrm{l}$ but not in non-diabetic counterparts.[24] This finding was 
confirmed by 2 longitudinal studies; Muraleedaran et al studied the effects of low testosterone (<10.4 nmol/l) and TTh on mortality in 581 men with T2DM. [6] After adjustment for confounders, mortality was higher in the low testosterone group. Further, the 174 men not on TTh were at significantly higher risk of mortality than the 64 men receiving TTh. We found similar results in 857 men with T2DM using a total testosterone cut-off of $12.0 \mathrm{nmol} / \mathrm{l}$ and free testosterone of $0.25 \mathrm{nmol} / \mathrm{l}$. [19,25]. Compared with men with low total or calculated free testosterone and not on TTh, mortality was lower in men with normal testosterone (Hazard Ratio (HR): 0.62, Cl: $0.41-0.94)$ and men with low testosterone on TTh (HR: $0.38, \mathrm{Cl}: 0.16-0.90)$. This benefit was independent of changes in cardiovascular/metabolic risk factors [29]. These data show that low serum testosterone levels have clinical implications, and accordingly, serum total and free testosterone treatment thresholds for TTh are identified; guidelines issued by the British Society for Sexual Medicine have indicated that men with total testosterone $<8 \mathrm{nmol} / /$ or free testosterone $<0.180 \mathrm{nmol} / \mathrm{I}$ usually require TTh while those with total testosterone $8-12 \mathrm{nmol} / / \mathrm{l}$ may require TTh depending on symptoms [30]. However, the relationship between extent of reduction in serum testosterone and particular clinical symptoms is unclear and, the establishing of universal, clinically useful cut-off values is problematic. Firstly, an assay standardisation approach may be required as marked between-method variation in the accuracy and precision of SHBG and testosterone assays has been identified (https://birminghamquality.org.uk/eqa-programmes/ster/ - accessed 20/05/2019) [31] and secondly, none of the commonly used guidelines include corresponding values for variables such as SHBG that mediate free testosterone levels. 


\section{Sex Hormone Binding Globulin}

Hydrophobic steroids such as testosterone are largely transported in serum by carrier proteins including SHBG and albumin. [32,33]. SHBG is central because its ability to bind testosterone mediates transport, serum levels of free/bioavailable and cellular uptake of testosterone and appears to offer in some men, a clinically useful insight into androgen status. [2,32,33,34,35]

SHBG, a homodimeric glycoprotein, is largely synthesised in the liver. [2] Each monomer has one steroid binding site allowing transport of two steroid molecules/dimer. In serum, SHBG binds steroids such as dihydrotestosterone and testosterone with high affinity; $\mathrm{K}_{\mathrm{a}} \sim 10^{9} \mathrm{I} / \mathrm{mol}$ while albumin, present in human serum at high concentration (typically $\sim 40 \mathrm{~g} / \mathrm{l}$ ) offers substantial capacity but low affinity ( $\mathrm{K}_{\mathrm{a}}$; $\left.\sim 3 X 10^{4} \mathrm{I} / \mathrm{mol}\right)$. [35,36,37,38,39] Cortisol binding globulin $\left(\mathrm{K}_{\mathrm{a}} 5 \cdot 3 \times 10^{6} \mathrm{l} / \mathrm{mol}\right)$ and orosomucoid $\left(\mathrm{K}_{\mathrm{a}} 3.0 \times 10^{5} \mathrm{I} / \mathrm{mol}\right)$ also bind the steroid weakly. [32,38,39,40,41] Accordingly, they often ignored in the context of testosterone and phenotype.

\section{Serum SHBG, total and free/bioavailable testosterone}

Various algorithms have been used to calculate free or bioavailable testosterone. $[38,39,40,41]$ The widely used Vermeulen et al model is based on mass-action binding and assumes one molecule of testosterone binds to one SHBG molecule [38]. Other more recent models are based on each SHBG monomer having a binding site that can receive one testosterone molecule. [42]

Figure 1 shows, for 3 total testosterone concentrations (median, 25\% and $75 \%$ percentile of our cohort of men with T2DM) [19] how changes in SHBG mediate levels of calculated bioavailable and free testosterone. By changing SHBG values within the observed distribution in men with T2DM, the free testosterone concentration can fall considerably when SHBG increases from the $25^{\text {th }}$ to $75^{\text {th }}$ 
percentile. For serum albumin, a protein that usually demonstrates much less variation, the extent of change in free testosterone is modest (data not shown). Thus, even allowing for possible errors in the binding parameters and, differences in the approaches used to derive the algorithms, it may be reasonable to consider values of free or bioavailable testosterone in "local units" as showing patterns of change.

Because of its high serum concentration, barely $1 \%$ of albumin binding sites in men are generally occupied while for SHBG, $36 \%$ of sites are occupied by testosterone, $20 \%$ by androgen metabolites or oestradiol and only $44 \%$ are unoccupied. [36] Dunn et al proposed that SHBG largely determines the serum distribution of sex steroids and that changes in its level will alter testosterone distribution [36].

Albumin-bound testosterone may also be bioavailable because binding is weak and interactions with the vascular wall may allow dissociation of steroid during flow through capillaries. $[43,44]$. Bioavailable may be a more useful measure of hormone status than total testosterone; for example, its fall during male aging is steeper and associated with features of adult onset TD. $[45,46,47,48]$

\section{Issues in Quantifying Free and Bioavailable testosterone.}

Determination of free or bioavailable testosterone experimentally or using algorithms is relatively demanding because of inter- and intra-laboratory imprecision of available methods and different values for binding parameters. Discrepancies between free testosterone values calculated using the Vermeulen et al approach and a variety of other algorithms or determined experimentally are reported. [37,38, $42,49,50,51,52]$ Recently, Zacharov et al proposed a more complex model of testosterone binding. [53] Thus, while it had been believed that testosterone 
associated to each SHBG site with the same affinity, Zacharov et al proposed that testosterone binding to one monomer affects the interaction of the next testosterone molecule with the unoccupied, second site and the second molecule is bound with a different affinity to the first indicating the process is allosteric. [53] Zakharov et al argued that SHBG binding of testosterone cannot be described by available algorithms and instead used an allosteric model to calculate free testosterone. [53] In samples from Framingham Heart Study subjects, levels calculated using a traditional algorithm were markedly lower than those obtained using an allosteric model; in subjects aged $<30$ years, free testosterone using a traditional model was $145.35 \pm 45.8(\mathrm{SD}) \mathrm{pg} / \mathrm{ml}$ and the allosteric model, $238.339 \pm 71.77(\mathrm{SD}) \mathrm{pg} / \mathrm{ml}$. The allosteric model gave values similar to those obtained using equilibrium dialysis. $[42,53]$

While there is no universally accepted method for determining free and bioavailable testosterone, an international expert consensus conference in 2015 stated that this analysis was important in the assessment of men with adult onset TD [54]. As clinicians (SR, GIH), we agree and consider free testosterone together with SHBG and total testosterone integral in routine patient screening and monitoring. Free testosterone measurements are particularly useful in the investigation of men with adult onset TD symptoms and a borderline total testosterone of $8-11 \mathrm{nmol} / \mathrm{l}$, though perhaps less so in men with total testosterone<8 nmol/l. $[55,56]$

\section{SHBG: Wide range of values in human serum}

The symptoms and characteristics of hypogonadism are nonspecific and varied and not always associated with low testosterone levels prompting interest in 
the relationship between SHBG (as an independent variable) and clinical phenotype [57]. While SHBG may not have a direct effect on clinical outcomes we might expect higher serum SHBG levels to be associated with greater morbidity/mortality as free/bioavailable testosterone levels would presumably be lower. Thus, increased SHBG causes decreased free testosterone, triggering luteinizing hormone release and increased testosterone production until free hormone levels are restored. An insight into the biological importance of SHBG may be gained by considering individuals who have no peptide. Vos et al described an extremely rare missense mutation that encoded a secretion defective SHBG variant that accumulated in cells. [58] A brother and sister, homozygotes for the mutant allele, had no detectable serum SHBG. In the brother, serum total testosterone levels were low but free levels appeared adequate. Gonadal development and sperm production and function appeared normal though he had symptoms of hypoandrogenism. The sister reported a late menarche and irregular menstrual cycles. These findings suggest SHBG is required for some of testosterone's anabolic activities but is not essential for male reproductive development [58].

It is noteworthy that considering a physiological role for SHBG is not helped by the finding that its serum concentrations vary during life and demonstrate marked inter- and intra-individual variation even in apparently healthy adults. [2] For example, Krakowsky et al [34] found a mean SHBG concentration in 1000 consecutive patients of $31.8 \pm 15.2 \mathrm{nmol} / \mathrm{l}$ (range $6-109 \mathrm{nmol} / \mathrm{l}$ ) while we found in 857 men with T2DM, concentrations between 7.9 - $185.5 \mathrm{nmol} / \mathrm{l}$ [59]. Further, during adulthood, SHBG levels increase with age though there is a wide variation in individuals stratified by young/old age. [34,59] 


\section{SHBG level and clinical phenotype.}

Much research shows the importance of SHBG in determining clinical phenotype. [3,57,59,60,61,62,63,64] For example, the European Male Aging Study showed men with normal total but low free testosterone (using the algorithm of Vermeulen et al [38]) had higher LH levels, more sexual and physical symptoms than men with normal total and free testosterone or men with low total and normal free testosterone levels. [21] Thus, low free testosterone, even with a normal total testosterone, was associated with adult onset TD, while low total testosterone with normal free was not. Studies in transgenic mice that overexpressed SHBG also show that androgen deficiency is apparent in individuals with normal or borderline levels of serum total testosterone. [61]

Many factors mediate serum peptide levels; hormones including thyroxine, insulin, insulin like growth factor-1, prolactin and, non-hormonal factors including physical activity, body weight, body-mass-index (BMI), waist-to-hip ratio, some drugs and diet modify SHBG levels. [2,59] SHBG levels are lower with increasing obesity and in patients with T2DM and a low level of SHBG is associated with increased risk of developing MetS, gestational diabetes and T2DM and the cardiovascular disease linked with these conditions. Furthermore, SHBG genetic variation has been proposed to contribute to the development of T2DM.

The above data raise issues of how closely serum SHBG levels are regulated and which of the varied factors that affect expression are most important. [65] Gyawali et al in a cross-sectional and longitudinal study identified various determinants of serum SHBG in men. [66] Baseline SHBG levels were positively associated with age, thyroxine and total testosterone and inversely with abdominal fat mass, triglycerides and oestradiol. Low SHBG levels largely reflect obesity. It was 
suggested that variation in SHBG reflects de novo hepatic lipogenesis and insulin resistance and that thyroid hormone may modulate circulating SHBG. High levels of serum sex steroids are associated with higher SHBG levels. [66]

\section{SHBG: An independent factor determining mortality?}

A range of metabolically active factors influence serum SHBG levels many of which are risk factors for clinically important phenotypes. Accordingly, establishing the independence of associations between SHBG and patient characteristics is important.

Recently, Tint et al [60] showed that elevated levels of SHBG and low levels of free testosterone were significantly and independently associated with all causemortality after adjustment for diabetes-related risk factors. The association of total testosterone with mortality weakened after such adjustment. We also investigated the impact of SHBG, age and related variables on mortality in 364 men with T2DM. [3] Age, SHBG and testosterone were significantly and independently associated with mortality. SHBG was associated with age, testosterone, statin use and MetS features. Mortality rate and age increased with SHBG quartiles. When pairwise combinations of age and SHBG dichotomized by median values were considered, the association of SHBG with mortality was age-dependent; firstly, age >66 years/SHBG >35 nmol/l was significantly associated (HR: $9.37, \mathrm{p}<0.001)$ with greater mortality $(22.45 \%)$ compared to age $\leq 66$ years/SHBG $\leq 35 \mathrm{nmol} / \mathrm{l}$ (mortality: $3.23 \%$ ) and secondly, SHBG $\leq 35 \mathrm{nmol} / \mathrm{l}$ was associated with decreased mortality in men $>66$ years (HR: 0.41, $p=0,037$, reference: $S H B G>35 \mathrm{nmol} / \mathrm{l})$ but in men $\leq 66$ years there was no significant difference in those with SHBG $>35 \mathrm{nmol} / \mathrm{l}(\mathrm{HR}: 1.73$, 
$\mathrm{p}=0.56$, reference: $\mathrm{SHBG} \leq 35 \mathrm{nmol} / \mathrm{l})$. By contrast, total testosterone $<12 \mathrm{nmol} / \mathrm{l}$ was significantly associated with increased mortality in both age groups. Thus, while the association of SHBG with mortality in T2DM men is mediated by age, that with total testosterone $<12 \mathrm{nmol} / /$ was found irrespective of age $<$ or $>66$ years.

These analyses demonstrate the cumulative effects of the risk phenotypes; age $>66$ years, total testosterone $<12 \mathrm{nmol} / \mathrm{l}$ and $\mathrm{SHBG}>35 \mathrm{nmol} / \mathrm{l}$. Men with two of factors demonstrated high mortality; age $>66$ years/SHBG $>35$ nmol/l: mortality $22.5 \%$ and age $>66$ years/total testosterone $<12 \mathrm{nmol} / \mathrm{l}:$ mortality $25.0 \%$. In men with all three risk variables, age $>66$ years/total testosterone $<12 \mathrm{nmol} / / / \mathrm{SHBG}>35 \mathrm{nmol} / \mathrm{l}$, mortality was $36.8 \%$. Thus, SHBG is linearly associated with age but its association with mortality is more evident in men aged>66 years (who also suffer higher mortality). In men with T2DM, the combination of low total testosterone, high SHBG and age $>66$ years is a principal risk category compared with other combinations. [3]

\section{SHBG, testosterone and age-related mortality.}

As both SHBG and mortality increase with age while both total and free testosterone levels fall (https://uroweb.org/wp-content/uploads/EAU-GuidelinesMale-Hypogonadism-2015.pdf - accessed on 20/05/2019) establishing prognosis (eg. mortality) in individual patients is difficult. One approach that demonstrates the association of inter-related variables with mortality at different ages is based on Benjamin Gompertz's observations that mortality increases exponentially with age. $[67,68,69]$, More recently we found in our cohort of men with T2DM that the relationship between age and mortality was as described by Gompertz. [25]

To determine how SHBG and testosterone influence age-related mortality in T2DM men who had not received TTh we determined the probability of each of the 
previously described 364 men with T2DM categorised by SHBG or testosterone, living or dying at a particular age. [3] We used a logistic regression model to derive the probability of mortality (dependent variable) with age (continuous variable) and SHBG and/or testosterone (dichotomized) as independent variables. Probability of mortality and $95 \%$ confidence intervals were plotted against age. If no overlap of the 95\% confidence intervals between treatment/no treatment lines was observed, we considered the treatment significantly altered the relationship between age and mortality. The approach allows a graphic demonstration of the impact of stratified levels of SHBG and/or testosterone (stratified by median values; SHBG 35nmol/l, total testosterone $12 \mathrm{nmol} / \mathrm{l}$ ) on mortality over a range of ages. Since age is the most significant predictor of death, finding that a variable alters this relationship gives an indication of its biological importance. The regression analyses (Table 1) were carried out sequentially, building with each successive model on the previous analysis. We ended with mortality as the dependent variable and age and a dichotomised combination of SHBG and total testosterone as independent variables (model 8). None of these men had received TTh and, accordingly, median values for SHBG $(35 \mathrm{nmol} / \mathrm{l})$ and total testosterone $(12 \mathrm{nmol} / \mathrm{l})$ are different from previous distributions where baseline values of the total cohort that included men who received TTh were used.

In logistic regression analyses we showed that individually, age (Model 1) and age and SHBG entered as independent variables (model 2) were significantly associated with mortality. When total testosterone was entered (with age) it was not significantly associated with mortality (model 3 ) though in an analysis (model 4) comprising all three variables, each was independently, significantly associated with mortality. As expected, increasing age and SHBG were associated with increased 
mortality with total testosterone inversely associated with mortality. Dichotomizing SHBG and total testosterone by their median values showed SHBG $>35 \mathrm{nmol} / \mathrm{l}$ and total testosterone $<12 \mathrm{nmol} / \mathrm{l}$ were individually and independently significantly associated with increased mortality (model 4). We then further studied the association between SHBG and mortality in men stratified by the median total testosterone of $12 \mathrm{nmol} / \mathrm{l}$. Interestingly, the association of SHBG $>35 \mathrm{nmol} / \mathrm{l}$ with mortality was not observed in men with testosterone $\geq 12 \mathrm{nmol} / \mathrm{l}$ (Model $6 \mathrm{~b}$ ) unlike in men with total testosterone $<12 \mathrm{nmol} / \mathrm{l}$ (Model 6a). Accordingly, we used combinations of SHBG and total testosterone (model 7) with age as independent variables and found men with total testosterone $<12 \mathrm{nmol} / \mathrm{l}$ and $\mathrm{SHBG}>35 \mathrm{nmol} / \mathrm{l}$ (reference) were at risk compared to the other 3 combinations. Model 8 shows that relative to other combinations of SHBG and testosterone, men with SHBG >35 nmol/I and testosterone $<12 \mathrm{nmol} / \mathrm{l}$ had the highest mortality risk. The model was used to calculate the probability of death and $95 \%$ confidence intervals for each man. Figure 2 shows the association between probability of mortality and age in these two groups. Mortality is greater in men with the combination of SHBG $>35 \mathrm{nmol} / \mathrm{l}$ and testosterone $<12 \mathrm{nmol} / \mathrm{l}$ though there is some overlap of $95 \% \mathrm{Cl}$ values after about 69 years indicating that, despite relatively small patient numbers, the combination of elevated SHBG and low total testosterone alters the relationship between age and mortality.

\section{Conclusions}

A paradox is apparent. While it is noteworthy that SHBG and T2DM and the MetS are positively associated with mortality, both conditions are negatively associated with SHBG. Thus, while high levels of SHBG are associated with 
increased all-cause mortality, levels of the peptide are inversely associated with insulin resistance and this may mediate the association between low serum testosterone and increased mortality in men with T2DM. [3,6,19,60,70]

Both SHBG and low total testosterone are identified as independent variables that mediate age-related mortality in men with T2DM. The more limited data available for free testosterone derived using a traditional algorithm are supportive of these findings. In a T2DM context free/bioavailable testosterone is integral in the development of disease phenotypes including mortality; low free testosterone was associated with mortality more strongly than either total testosterone or SHBG. [60] Clearly, apart from inter-individual variation in SHBG and testosterone levels, other host characteristics such as androgen sensitivity and the functionality of androgen receptors are potential factors affecting outcome. [71,72]

A further complication may be reports indicating SHBG acts as more than just a carrier protein in specific instances. It has also been suggested that SHBG could affect mortality by a mechanism that is independent of its role in testosterone metabolism such as regulation of cell proliferation. $[42,74]$ These data remain to be assessed.

This review has demonstrated associations between SHBG and clinical phenotypes with particular focus on mortality. While the mechanism is uncertain, it might be speculated that the association is determined by the actions of the globulin in determining serum levels of free/bioavailable testosterone. However, the association of SHBG with mortality is independent of free and total hormone perhaps hinting at further functions of the globulin and/or the need for better methodologies to quantify these analytes and/or a role for other steroid hormones transported by SHBG. $[31,42,73,74,75,76]$ 
Given the association of SHBG with mortality, it is tempting to speculate on the feasibility and usefulness of clinical modification of serum globulin levels. Given the association of SHBG with mortality, it is tempting to speculate on the feasibility and usefulness of clinical modification of serum globulin levels. A wide range of factors including widely used drugs such as statins, mediate SHBG levels. For example, in men with T2DM, Stanworth et al. showed that atorvastatin therapy (but not simvastatin) was associated with significantly reduced total testosterone and a trend towards reduced SHBG levels and we reported that statin therapy was associated with a significant reduction in SHBG levels. [3,77] Alternatively, vegetarian, vegan and low calorie diets may be associated with higher serum SHBG concentrations though changes in testosterone levels have varied between studies. [78] It is not known if any of these approaches have clinical relevance in the context of adult onset TD and, in our view use of therapy to modify SHBG levels is, given current uncertainties, inappropriate. 


\section{References}

[1] Khera M, Broderick GA, Carson CC, Dobs AS, Faraday MM, Goldstein I, et al. Adult-Onset Hypogonadism Mayo Clin Proc 2016; 91: 908-926.

[2] Hammond GL. Diverse Roles for Sex Hormone-Binding Globulin in Reproduction. Biology of Reproduction 2011; 85:431-441

[3] Ramachandran S, Strange RC, Fryer AA, Hackett GI. The association of sex hormone binding globulin with mortality is mediated by age and is independent of total testosterone in men with type 2 diabetes. Andrology. 2018; 6:846-853 [4] Kelly DM, Hugh Jones T. Testosterone: a metabolic hormone in health and disease J Endocrinol 2013; 217: R25-R45

[5] Pye SR, Huhtaniemi IT, Finn JD Lee DM, O'Neill TW, Tajar A, et al. Late-onset hypogonadism and mortality in aging Men J Clin Endocrinol Metab 2014; 99: 13571366.

[6] Muraleedaran V, Marsh H, Kapoor D, Channer KS, Jones TH. Testosterone deficiency is associated with increased risk of mortality and testosterone replacement improves survival in men with type 2 diabetes. Eur J Endocrinol 2013; 169:725-733

[7] Fabbri E, An Y, Gonzalez-Freire M, Zoli M, Marcello Maggio M, Studenski SA, et al. Bioavailable Testosterone Linearly Declines Over A Wide Age Spectrum in Men and Women From The Baltimore Longitudinal Study of Aging. J Gerontol A Biol Sci Med Sci. 2016; 71: 1202-1209

[8] Kaufman JM, Vermeulen A. The decline of androgen levels in elderly men and its clinical and therapeutic implications. Endocr Rev. 2005; 26:833- 876.

[9] Shores MM, Matsumoto AM, Sloan KL, Kivlahan KL. Low serum testosterone and mortality in male veterans. Arch Intern Med. 2006; 166:1660-1665. 
[10] Livingston M, Kalansooriya A, Hartland AJ, Ramachandran S, Heald A. Serum testosterone levels in male hypogonadism: Why and when to check-A review. Int J Clin Pract. 2017; 71:e12995.

[11] Ford ES. Prevalence of the metabolic syndrome defined by the International Diabetes Federation among adults in the U.S. Diabetes Care 2005; 28: 2745-2749 [12] Hackett G, Cole N, Deshpande A, Popple M, Kennedy D, Wilkinson P. Biochemical hypogonadism and type 2 diabetes in primary care. Br J Diab Vasc Dis. 2009; 9: 226-231.

[13] Muraleedaran V, Jones TH. Testosterone and the metabolic syndrome. Ther Adv Endocrinol Metab. 2010;1: 207-223.

[14] Kupelian V, Page ST, Araujo AB, Travison TG, Bremner WJ, McKinlay JB. Low sex hormone-binding globulin, total testosterone, and symptomatic androgen deficiency are associated with development of the metabolic syndrome in nonobese men. J Clin Endocrinol Metab. 2006; 91:843-850.

[15] Muller M, Grobbee DE, den Tonkelaar I, Lamberts SW, van der Schouw YT. Endogenous sex hormones and metabolic syndrome in aging men. J Clin Endocrinol Metab. 2005; 90:2618-2623.

[16] Shipman KE, Strange RC, Ramachandran S. Use of fibrates in the metabolic syndrome: a review. World J Diabetes. 2016; 7: 74-88.

[17] Bebb R, Millar A, Brock G. Sexual Dysfunction and Hypogonadism in Men With Diabetes. Diabetes Canada Clinical Practice Guidelines Expert Committee. Can J Diabetes 2018; 42: S228-S233

[18] Ma RC, So WY, Yang X, Yu LW, Kong AP, Ko GT, et al. Erectile dysfunction predicts coronary heart disease in type 2 diabetes. J Am Coll Cardiol. 2008; $51: 2045-2050$ 
[19] Hackett G, Heald AH, Sinclair A, Jones PW, Strange RC, Ramachandran S. Serum testosterone, testosterone replacement therapy and all-cause mortality in men with type 2 diabetes: retrospective consideration of the impact of PDE5 inhibitors and statins. Int J Clin Pract. 2016; 70: 244-253.

[20] Dong JY, Zhang YH, Qin YQ. Erectile Dysfunction and Risk of Cardiovascular Disease Meta-Analysis of Prospective Cohort Studies. J Am Coll Cardiol. 2011; $58: 1378-1385$.

[21] Wu FC, Tajar A, Beynon JM, Pye SR, Silman AJ, Finn JD, et al. Identification of late-onset hypogonadism in middle-aged and elderly men. N Engl J Med. 2010; 363:123-35.

[22] Pye SR, Huhtaniemi IT, Finn JD, Lee DM, O'Neill TW, Tajar A, et al. Late-onset hypogonadism and mortality in aging Men. J Clin Endocrinol Metab. 2014; 99: 13571366.

[23] Maggi M, Wu FC, Jones TH, Jackson G, Behre HM, Hackett G, et al.

Testosterone treatment is not associated with increased risk of adverse cardiovascular events: results from the Registry of Hypogonadism in Men (RHYME). Int J Clin Pract. 2016; 10:843-852.

[24] Shores M, Smith NL, Forsberg CW, Anawalt BD, Marsumoto AM. Testosterone treatment and mortality in men with low testosterone. J Clin Endocrin Metab. 2012; 97: 2050-2058.

[25] Hackett G, Jones PW, Strange RC, Ramachandran S. Statin, testosterone and phosphodiesterase 5-inhibitor treatments and age-related mortality in diabetes. World J Diabetes 2017; 8: 104-111.

[26] Yeap H, Alfonso SAP, Chubb DJ, Handelsman GJ, Hankey OP, Almeida J, et al. In Older Men an Optimal Plasma Testosterone Is Associated with Reduced All- 
Cause Mortality and Higher Dihydrotestosterone With Reduced Ischemic Heart Disease Mortality, While Estradiol Levels Do Not Predict Mortality. J Clin Endocrinol Metab. 2014; 99: E9-E18.

[27] Araujo AB, Dixon JM, Suarez EA, Murad MH, Guey LT, Wittert GA Endogenous testosterone and mortality in men: a systemic review and meta-analysis. J Clin Endocrinol Metab. 2011;96: 3007-3019.

[28] Haring R, Völzke H, Steveling A, Krebs A, Felix SB, Schöfl C, et al. Association of Low Testosterone Levels with All-Cause Mortality by different cut-offs from recent studies. Eur Heart J. 2010; 31:1494-1501

[29] Hackett GI, Cole N, Mulay A, Strange RC, Ramachandran S. Long-term Testosterone Therapy in Type 2 Diabetes is associated with reduced Mortality without improvement in conventional cardiovascular risk factors. BJUInt 2019; 123 : 519-29

[30] Hackett G, Kirby M, Edwards D, Jones TH et al. British Society for Sexual Medicine guidelines on adult testosterone deficiency, with statements for UK practice. J Sex Med 2017; 14: 1504 - 1523

[31] Cao Z, Botelho JC, Rej R, Vesper H. Accuracy-based proficiency testing for testosterone measurements with immunoassays and liquid chromatography-mass spectrometry. Clin Chim Acta 2017; 469: 31 - 36

[32] Hammond GL Plasma steroid-binding proteins: primary gatekeepers of steroid hormone action. Endocrinol. 2016 230:R13-R25.

[33] Laurent MR, Hammond GL, Blokland M, Jardí F, Antonio L, Dubois V, et al. Sex hormone-binding globulin regulation of androgen bioactivity in vivo: validation of the free hormone hypothesis. Sci Rep. 2016; 6: 35539.doi: 
[34] Krakowsky Y, Conners W, Morgentaler A. Serum Concentrations of Sex Hormone-binding Globulin Vary Widely in Younger and Older Men: Clinical Data from a Men's Health Practice. Eur Urol Focus. 2017; http://dx.doi.org/10.1016/j. euf.2017.05.007 http://dx.doi.org/10.1016/j.euf.2017.05.007 2405-4569/@ 2017 European Association of Urology.

[35] Heinrich-Balard L, Zeinyeh W, Déchaud H, Rivory P, Roux A, Pugeat M, et al. Inverse relationship between hSHBG affinity for testosterone and hSHBG concentration revealed by surface plasmon resonance. Mol Cell Endocrinol. 2015; 399:201-207.

[36] Dunn JF, Nisula BC, Rodbard D. Transport of steroid hormones: binding of 21 endogenous steroids to both testosterone-binding globulin and corticosteroid-binding globulin in human plasma. J Clin Endocrinol Metab. 1981; 53:58-68.

[37]. Cooke RR, Mclntosh JE, Murray-Mclntosh RP. Effect of cortisol on percentage of non-sex-hormone-bound steroid: implications for distribution of steroids on binding proteins in serum. Clin Chem 1996; 42: 249-254.

[38] Vermeulen A, Verdonck L, Kaufman JM. A critical evaluation of simple methods for the estimation of free testosterone in serum. J Clin Endocrinol Metab. 1999; $84: 3666-3672$ [39] Mazer NA. A novel spreadsheet method for calculating the free serum concentrations of testosterone, dihydrotestosterone, estradiol, estrone and cortisol: with illustrative examples from male and female populations. Steroids. $2009 ; 74: 512-$ 519.

[40] Södergard R, Bäckström T, Shanbhag V, Carstensen H. Calculation of free and bound fractions of testosterone and estradiol-17 beta to human plasma proteins at body temperature. J Steroid Biochem 1982; 16: 801-810 
[41] Kerkay J, Westphal U. Steroid-protein interactions, XIX: complex formation between alpha 1-acid glycoprotein and steroid hormones. Biochim Biophys Acta. 1968;170: 324-333.

[42] Goldman AL, Bhasin S, Wu FCW, Krishna M, Matsumoto AM, Jasuja RA. Reappraisal of Testosterone's Binding in Circulation: Physiological and Clinical Implications. Endocr Rev. 2017; 38:302-324.

[43] Manni A, Pardridge WM, Cefalu W, Nisula BC, Bardin CW, Santner SJ, et al.Bioavailability of albumin-bound testosterone J Clin Endocrinol Metab. 1985; $61: 705-710$

[44] Pardridge WM. Serum bioavailability of sex steroid hormones Clin Endocrinol Metab. 1986;15: 259-278

[45] Morley JE, Perry HM. Androgen treatment of male hypogonadism in older males J Steroid Biochem Mol Biol 2003; 85: 367-373

[46] Ferrini RL, Barrett-Connor E. Sex hormones and age: a cross-sectional study of testosterone and estradiol and their bioavailable fractions in community-dwelling men. Am J Epidemiol 1998; 15: 750-754

[47] Van den Beld AW, de Jong FH, Grobbee DE, Pols HA, Lamberts SW. Measures of bioavailable serum testosterone and estradiol and their relationships with muscle strength, bone density, and body composition in elderly men. J Clin Endocrinol Metab 2000; 85:3276-3282. [48] Chu LW, Tam S, Wong RL, Yik PY, Song Y, Cheung BM, et al. Bioavailable testosterone predicts a lower risk of Alzheimer's disease in older men. $\mathrm{J}$ Alzheimers Dis 2010; 21:1335-1345. 
[49] Ly LP, Handelsman DJ. Empirical estimation of free testosterone from testosterone and sex hormone-binding globulin immunoassays. Eur J Endocrinol. 2005; 152: 471-478

[50] Giton F, Guéchot J, Fiet J. Comparative determinations of non SHBG-bound serum testosterone, using ammonium sulfate precipitation, concanavalin A binding or calculation in men. Steroids. 2012; 77: 1306-1311

[51] Mendel, C.M. 1989. The free hormone hypothesis: a physiologically based mathematical model. Endocr Rev.1989; 10:232-274.

[52] Siiteri PK, Murai JT, Hammond GL, Nisker JA, Raymoure WJ, Kuhn RW. The serum transport of steroid hormones. Recent Prog Horm Res. 1982; 38:457-510. [53] Zakharov MN, Bhasin S, Travison TG, Xue R, Ulloor J, Vasan RS, et al. A multistep, dynamic allosteric model of testosterone's binding to sex hormone binding globulin. Mol Cell Endocrinol . 2015; 399:190-200

[54] Khera M, Adaikan G, Buvat J, Carrier S, El-Meliegy A, Hatzimouratidis, et al. Diagnosis and treatment of testosterone deficiency: Recommendations from the forth International Consultation for Sexual Medicine (ICSM 2015). J Sex Med 2016; 13 : 1787-1804.

[55] Morgentaler A, Zitzmann M, Traish AM, Fox AW, Hugh Jones T, Maggi M, et al. Fundamental Concepts Regarding Testosterone Deficiency and Treatment: International Expert Consensus Resolutions. Mayo Clin Proc. 2016; 91:881-896 [56] Antonio L, Wu FCW, O’Neill TW, Pye SR, Ahern TB, Laurent MR, et al. Low free testosterone is associated with hypogonadal signs and symptoms in men with normal total testosterone. J Clin Endocrinol Metab. 2016; 101:2647-2657. 
[57] Rastrelli G, Corona G, Cipriani S, Mannucci E, Maggi M. Sex hormone-binding globulin is associated with androgen deficiency features independently of total testosterone. Clin Endocrinol. 2018; 88:556-564.

[58] Vos MJ, Mijnhout GS, Rondeel JM, Baron W, Groeneveld PH. Sex hormone binding globulin deficiency due to a homozygous missense mutation. J Clin Endocrin Metab 2014; 99: E1798-E1802.

[59] Thaler MA, Seifert-Klauss V, Luppa PB. The biomarker sex hormone-binding globulin. From established applications to emerging trends in clinical medicine. Best Practice \& Research Clinical Endocrinology \& Metabolism 2015; 29: 749-760 [60] Tint AN, Hoermann R, Wong H, Ekinci El, Maclsaac RJ, Jerums G, et al. Association of sex hormone-binding globulin and free testosterone with mortality in men with type 2 diabetes mellitus. Eur J Endocrinol 2016; 174: 59-68.

[61] Laurent MR. Hammond GL, Blokland M, Jardí F, Antonio L, Dubois V, et al. Sex hormone-binding globulin regulation of androgen bioactivity in vivo: validation of the free hormone hypothesis. Sci Rep 2016; 6: 35539

[62] Ding E, Song Y, Manson JE, Hunter DJ, Lee CC, Rifai N, et al. Sex HormoneBinding Globulin and Risk of Type 2 Diabetes in Women and Men. N Engl J Med. 2009; 361: 1152-1163.

[63] Brand JS, Rovers MM, Yeap BB, Schneider HJ, Tuomainen TP, Haring R, et al. Testosterone, sex hormone binding globulin and the metabolic syndrome in men: an individual participant data meta-analysis of observational studies. PLoS One 2014: 9:e100409.

[64] Laaksonen DE, Niskanen L, Punnonen K, Nyyssönen K, Tuomainen TP, Valkonen VP, et al. Testosterone and sex hormone-binding globulin predict the 
metabolic syndrome and diabetes in middle-aged men. Diabetes Care. 2004; 27:1036-1041.

[65] Winters SJ, Gogineni J, Karegar M, Scoggins C, Wunderlich CA, Baumgartner R, et al. Sex Hormone-Binding Globulin Gene Expression and Insulin Resistance. J Clin Endocrinol Metab 2014; 99: E2780 - E2788. [66] Gyawali P, Martin SA, Heilbronn LK, Vincent AD, Jenkins AJ, Januszewski AS, et al. Cross-sectional and longitudinal determinants of serum sex hormone binding globulin (SHBG) in a cohort of community-dwelling men. PLoS ONE 2018;13: e0200078.

[67] Kirkwood TBL. Deciphering death: a commentary on Gompertz (1825) 'On the nature of the function expressive of the law of human mortality, and on a new mode of determining the value of life contingencies. Phil Trans R Soc. 2015; 370: 20140379 doi:10.1098/rstb.2014.0379.

[68] Hallen A. Makeham's addition to the Gompertz law re-evaluated. Biogerontology $2009 ; 10: 517-522$.

[69] Vaupel JW. Biodemography of human ageing. Nature 2010; 464: 536-542. [70] Khaw KT, Dowsett M, Folkerd E, Bingham S, Wareham N, Luben R, et al. Endogenous testosterone and mortality due to all causes, cardiovascular disease, and cancer in men: European Prospective Investigation into Cancer in Norfolk (EPIC-Norfolk) prospective population study. Circulation. 2007; 116: 2694-2701 [71] Zitzmann M. The role of the CAG repeat androgen receptor polymorphism in andrology. Front Horm Res. 2009; 37: 52-61.

[72] Stanworth RD, Akhtar S, Channer KS, Jones TH. The role of androgen receptor CAG repeat polymorphism and other factors which affect the clinical response to 
testosterone replacement in metabolic syndrome and type 2 diabetes: TIMES2 substudy. Eur J Endocrinol. 2013 21;170:193-200.

[73] Hammes A, Andreassen TK, Spoelgen R, Raila J, Hubner N, Schulz H, et al. Role of endocytosis in cellular uptake of sex steroids. Cell 2005; 122: 751-762 [74] Rosner W, Hryb DJ, Kahn SM, Nakhla AM, Romas NA. Interactions of sex hormone-binding globulin with target cells. Mol Cell Endocrinol. 2010; 316: 79-85. [75] Finkelstein JS, Lee H, Burnett-Bowie S-AM, Pallais JC, Yu EW, Borges LF, et al. Gonadal Steroids and Body Composition, Strength, and Sexual Function in Men. N Engl J Med. 2013; 369: 1011-1022.

[76] Ramachandran S, Livingston M, Hackett G, Strange RC. Should laboratory assay quality be described in study publications and clinical guidelines? A focus on testosterone assay performance. Edorium J Biochem 2019; 3:100007B01SR2019. [77] Stanworth RD, Kapoor DJ, Channer KS, Jones TH, Statin Therapy Is Associated With Lower Total but Not Bioavailable or Free Testosterone in Men With Type 2 Diabetes. Diabetes Care 2009; 32:541-546

[78] La J, Roberts NH, Yafi FA. Diet and Men's Sexual Health. Sex Med Reviews 2017; 6: 54-68. 
Figure 1. Calculated free testosterone and bioavailable testosterone levels at median (32.5 nmol/l) and inter quartile range (24.2 / $45.1 \mathrm{nmol} / \mathrm{l})$ of SHBG and median $(11.4 \mathrm{nmol} / \mathrm{l})$ and inter quartile range $(8.3 \mathrm{nmol} / \mathrm{l} / 14.8 \mathrm{nmol} / \mathrm{l})$ of total Testosterone concentrations in men with T2DM [19]

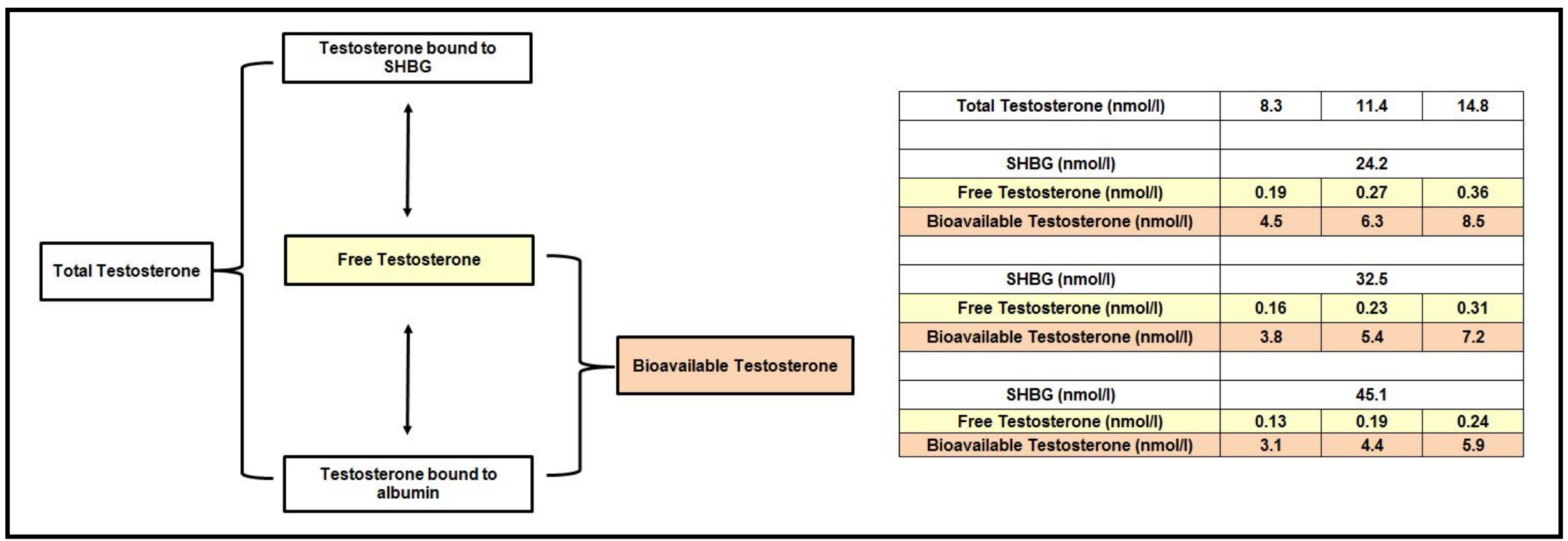

Calculated free testosterone and bioavailable testosterone levels were estimated using the algorithm by Vermeulen et al [26] with albumin concentrations at a default value of $43 \mathrm{~g} / \mathrm{l}$.

Other proteins (CBG / orosomucoid) are not included in the figure as they are not included in the Vermeulen algorithm. 
Figure 2: Association between probability of mortality and age. Estimated mortality probability and $95 \% \mathrm{Cl}$ (in men with $\mathrm{T} 2 \mathrm{DM}$ between 65 - 80 years) from the fitted logistic regression (Table 1) was calculated from the logistic regression analysis (Model 8 ) and plotted against age at death or final visit.

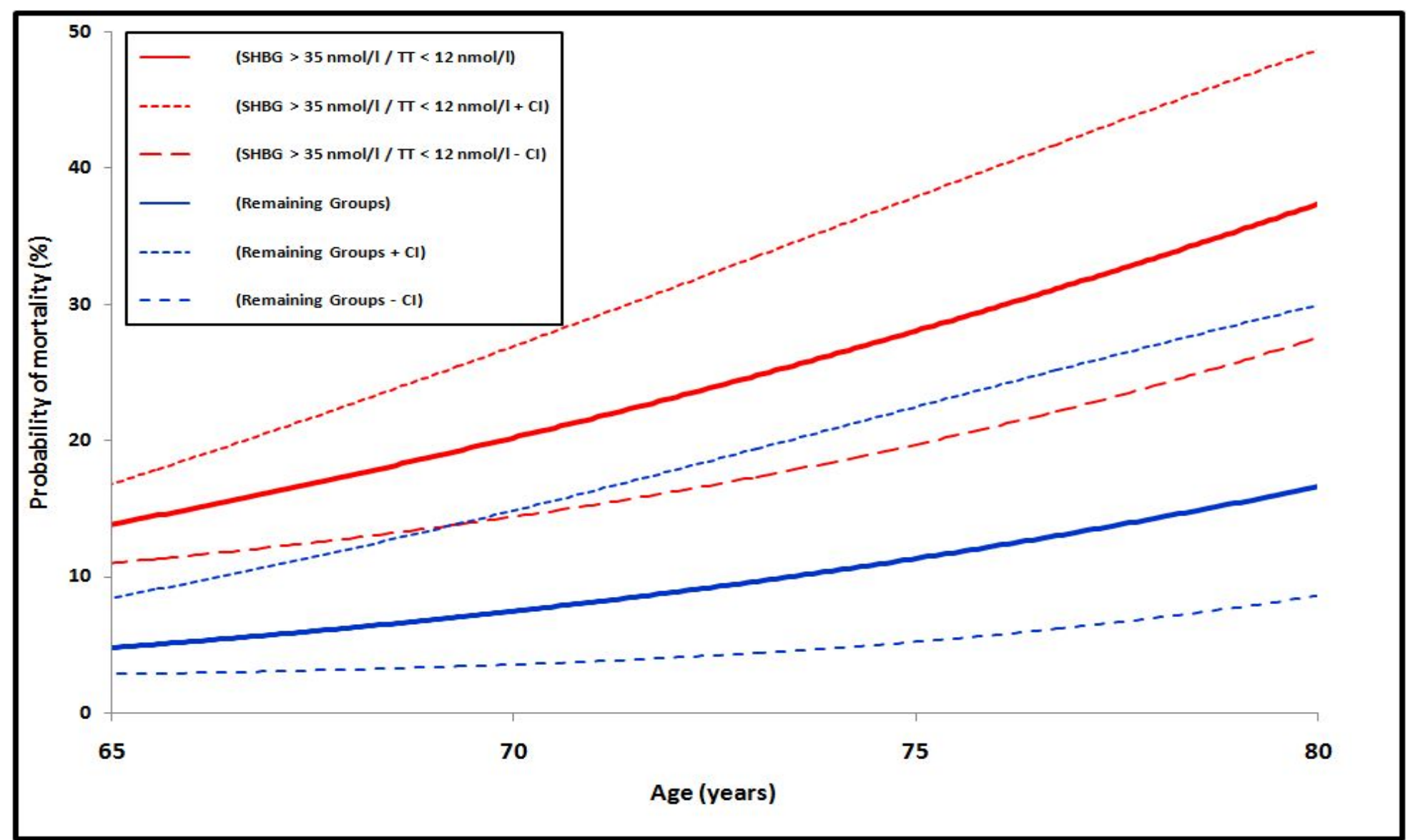


Disclosure Statement. Professor Geoffrey I Hackett has received honoraria for acting as a speaker for Bayer plc who provided the grant. Professor Sudarshan Ramachandran has received educational grants to attend meetings and honoraria for serving as a speaker for Besins Health Care Ltd. Professor Geoffrey I Hackett has spoken at national and international meetings on testosterone and PDE5I inhibitor treatments in men and sat on the committee of the European Society for Sexual Medicine. Professor Richard C Strange has no disclosures.

\section{Acknowledgements}

We thank Dr lan Nimmo for very helpful insights. The study was supported by a grant from Bayer to the Institute of Diabetes for Older People, Beds and Herts Postgraduate Medical School, University of Bedfordshire (ref BSP-SOP-040) to cover practice expenses. The sponsor had no role in study design, statistical analysis, findings or preparation of manuscripts. Administrative, technical or material support was provided by Mrs Sally Hackett and Mrs Alice Blakey. 
Table 1: Logistic regression models showing association between age and mortality (dichotomous dependent variable) in men with T2DM in the presence of SHBG and / or TT (either as continuous variables or stratified categories) in the total cohort (Models 1, 2, $3,4,5,7$ and 8 ) or when stratified by TT of $12 \mathrm{nmol} / \mathrm{l}$ (Models $6 \mathrm{a}, 6 \mathrm{~b}$ ).

\begin{tabular}{|c|c|c|}
\hline - & OR (95\% Cl) & $\underline{p}$ \\
\hline$\frac{\text { Model } 1, n=364}{\text { Age (years) }}$ & $1.10(1.07-1.13)$ & $<0.001$ \\
\hline $\begin{array}{c}\text { Model } 2, \mathrm{n}=364 \\
\text { Age (years) } \\
\text { SHBG }(\mathrm{nmol} / \mathrm{l})\end{array}$ & $\begin{array}{l}1.10(1.05-1.14) \\
1.02(1.00-1.03)\end{array}$ & $\begin{array}{l}<0.001 \\
0.015\end{array}$ \\
\hline $\begin{array}{c}\text { Model 3, } n=362 \\
\text { Age (years) } \\
\pi(n \text { mol } / \mathrm{l})\end{array}$ & $\begin{array}{l}1.10(1.06-1.15) \\
0.97(0.91-1.04)\end{array}$ & $\begin{array}{r}<0.001 \\
0.38\end{array}$ \\
\hline $\begin{array}{c}\text { Model } 4, \mathrm{n}=362 \\
\text { Age (years) } \\
\text { SHBG }(\mathrm{nmol} / \mathrm{l}) \\
\Pi(\mathrm{nmol} / \mathrm{l})\end{array}$ & $\begin{array}{l}1.08(1.04-1.13) \\
1.03(1.01-1.05) \\
0.91(0.85-0.98)\end{array}$ & $\begin{array}{l}<0.001 \\
0.001 \\
0.015\end{array}$ \\
\hline $\begin{array}{c}\frac{\text { Model } 5, \mathrm{n}=362}{\text { Age (years) }} \\
\\
\text { SHBG } \leq 35 \mathrm{nmol} / \mathrm{l} \\
\text { SHBG }>35 \mathrm{nmol} / \mathrm{l} \\
\mathrm{TT}<12 \mathrm{nmol} / \mathrm{l} \\
\Pi \geq 12 \mathrm{nmol} / \mathrm{l}\end{array}$ & $\begin{array}{c}1.08(1.04-1.13) \\
\text { reference } \\
2.54(1.14-5.66) \\
\text { reference } \\
0.37(0.17-0.81)\end{array}$ & $\begin{array}{l}<0.001 \\
0.022\end{array}$ \\
\hline $\begin{array}{c}\text { Model 6a }(\mathrm{TT}<12 \mathrm{nmol} / \mathrm{l}), \mathrm{n}=18 \\
\text { Age (years) } \\
\text { SHBG } \leq 35 \mathrm{nmol} / \mathrm{l} \\
\text { SHBG }>35 \mathrm{nmol} / \mathrm{l}\end{array}$ & $\begin{array}{l}1.09(1.03-1.15) \\
\quad \text { reference } \\
2.83(1.15-6.97)\end{array}$ & $\begin{array}{l}0.001 \\
0.023\end{array}$ \\
\hline $\begin{array}{c}\text { Model } 6 \mathrm{~b}(\mathrm{TT} \geq 12 \mathrm{nmol} / \mathrm{l}), \mathrm{n}=18 \\
\text { Age (years) } \\
\text { SHBG } \leq 35 \mathrm{nmol} / \mathrm{l} \\
\text { SHBG }>35 \mathrm{nmol} / \mathrm{l}\end{array}$ & $\begin{array}{l}1.09(1.03-1.16) \\
\text { reference } \\
1.75(0.36-8.37)\end{array}$ & $\begin{array}{l}0.006 \\
0.49\end{array}$ \\
\hline 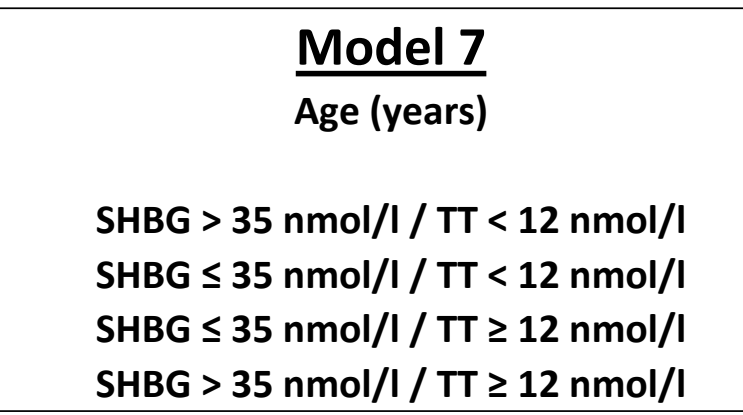 & $\begin{array}{c}1.09(1.05-1.14) \\
\text { reference } \\
0.35(0.14-0.86) \\
0.19(0.04-0.95) \\
0.34(0.14-0.80) \\
\end{array}$ & $\begin{array}{l}0.022 \\
0.043 \\
0.013\end{array}$ \\
\hline $\begin{array}{c}\frac{\text { Model } 8}{\text { Age (years) }} \\
\text { SHBG }>35 \mathrm{nmol} / / / \mathrm{TT}<12 \mathrm{nmol} / \mathrm{I} \\
\text { Remaining groups } \\
\text { SHBG } \leq 35 \mathrm{nmol} / / / \pi<12 \mathrm{nmol} / \mathrm{l} \\
\text { SHBG } \leq 35 \mathrm{nmol} / / / \pi \geq 12 \mathrm{nmol} / \mathrm{I} \\
\mathrm{SHBG}>35 \mathrm{nmol} / / / \pi \geq 12 \mathrm{nmol} / \mathrm{I}\end{array}$ & $\begin{array}{l}1.08(1.06-1.11) \\
3.05(1.43-6.53) \\
\text { reference }\end{array}$ & $\begin{array}{l}<0.001 \\
0.004\end{array}$ \\
\hline
\end{tabular}


Figure 1. Calculated free testosterone and bioavailable testosterone levels at median ( $32.5 \mathrm{nmol} / \mathrm{l})$ and inter quartile range $(24.2 / 45.1 \mathrm{nmol} / \mathrm{l})$ of SHBG and median $(11.4 \mathrm{nmol} / \mathrm{l})$ and inter quartile range $(8.3 \mathrm{nmol} / \mathrm{l} /$ $14.8 \mathrm{nmol} / \mathrm{l})$ of total Testosterone concentrations in men with T2DM [19]

$162 \times 121 \mathrm{~mm}(300 \times 300 \mathrm{DPI})$ 
Figure 2: Association between probability of mortality and age. Estimated mortality probability and $95 \% \mathrm{CI}$ (in men with T2DM between 65 - 80 years) from the fitted logistic regression (Table 1) was calculated from the logistic regression analysis (Model 8) and plotted against age at death or final visit.

$162 \times 121 \mathrm{~mm}(300 \times 300 \mathrm{DPI})$ 